\title{
Kompass für Vollkeramik-Restaurationen
}

Keramisch denken, keramisch präparieren - nur so können hochwertige, langlebige vollkeramische Restaurationen entstehen. Um alle Präparation- und Bearbeitungsregeln schnell und einfach „zur Hand" zu haben, hat Komet ein praktisches kleines Ringbuch entworfen. Dieser kostenlose Kompass führt auf 20 Seiten durch die keramikgerechte Präparation und Bearbeitung. Präparationsempfehlungen gehen dabei praktischerweise Hand in Hand mit der Vorstellung diverser Instrumente bzw. Sets, die Komet rund um die Präparation und Bearbeitung von Keramik speziell entwickelt hat. Dazu zählen die beiden Experten-Sets 4562ST (für Keramik-Inlays und Teilkronen) und 4573ST (für Keramik-Kronen), die diamantierten Schallspitzen SFM7 und SFD7 für die approximale Kavitätenpräparation von Prämolaren und Molaren, die Sets 4637 und 4622 für die souveräne Bearbeitung/Anpassung von Zirkonoxid sowie

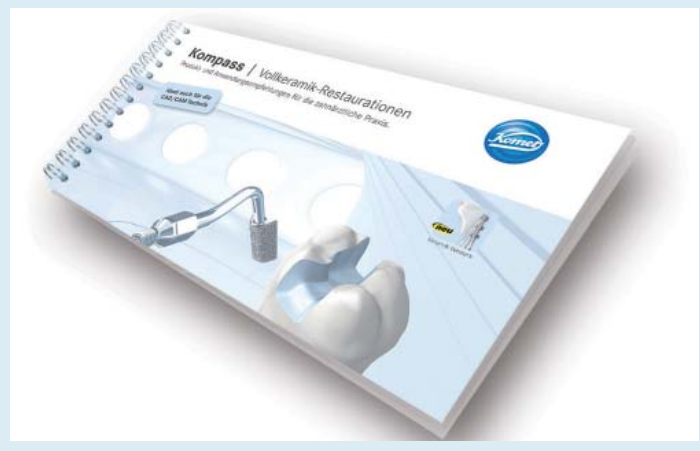

der Kronentrenner 4ZR. Damit bietet der neue Kompass Zahnärzten die Chance, korrekt und souverän mit Keramik umzugehen: Fordern Sie ihn an, unkompliziert und kostenlos!

Nach einer Pressemitteilung der

Komet Dental Gebr. Brasseler GmbH \& Co. KG,

Lemgo

Internet: www.kometdental.de 